http://jmscr.igmpublication.org/home/

ISSN (e)-2347-176x ISSN (p) 2455-0450

crossref DOI: https://dx.doi.org/10.18535/jmscr/v8i7.42

Journal Of Medical Science And Clinical Research

\title{
Comparison of Prophylactic Ilioinguinal Neurectomy and Ilioinguinal Nerve Preservation in Open Inguinal Hernia Repair: A Prospective Study
}

\author{
Authors \\ Dr Grace Lalitha Priya Uppada ${ }^{1^{*}}$, Dr Balla Mallayya ${ }^{2}$, Dr P. Sankara Rao ${ }^{3}$ \\ ${ }^{1}$ Postgraduate, Department of General Surgery, GEMS, Srikakulam \\ ${ }^{2}$ Professor, Department of General Surgery, GEMS, Srikakulam \\ ${ }^{3}$ Assistant Professor, Department of General Surgery, GEMS, Srikakulam \\ *Corresponding Author \\ Dr Grace Lalitha Priya Uppada
}

\begin{abstract}
Chronic post hernioplasty groin pain is a significant complication following inguinal hernial repair lasting for more than three months after surgery. ${ }^{[1]}$ Routine ilioinguinal neurectomy has been proposed as a means to avoid this complication. ${ }^{[2]}$ The motive of this study was to evaluate prophylactic routine ilioinguinal nerve excision compared to nerve preservation of chronic groin pain and other sensory symptoms when performing the surgery.

Sixty patients who underwent unilateral open mesh repair of inguinal hernia were included in the study with an elective division of the ilioinguinal nerve in 30 patients (Group A) and preservation in 30 patients (Group B). The patients were evaluated for postoperative pain, other sensory symptoms, and interference with activities of daily living after 1 month, 4 months, and 8 months of surgery by using the SF36 questionnaire.

In our study, we found that the incidence, as well as the severity of pain, is far higher in the nerve preservation study group as opposed to the neurectomy study group.

Prophylactic neurectomy can be an appropriate solution in the prevention of chronic groin pain following Lichtenstein inguinal hernia repair. Hypoesthesia is not a significant complication following ilioinguinal neurectomy and does not add much to the morbidity of the patient.There is no marked difference in the health-related quality of life in either of the study groups.

Keywords: Chronic, Groin pain, Ilioinguinal nerve, Neurectomy.
\end{abstract}

\section{Introduction}

Hernias are among the oldest known afflictions of humankind, and surgical repair of inguinal hernias are among the most common general surgical procedures performed today. ${ }^{[3]}$ Despite laparoscopic hernia repairs becoming popular today, Lichtenstein repair for inguinal hernia is the most commonly used to repair and is still the Gold Standard for Inguinal hernia repairs. ${ }^{[4,5]}$
Recently, with more attention to patient outcomes, Chronic post hernioplasty groin pain is a significant complication following inguinal hernial repair lasting for more than three months after surgery. ${ }^{[1]}$. Several large series with systematic follow-up have reported pain rates ranging from $29 \%$ to $76 \% .{ }^{[6,7]}$ Chronic groin pain can be classified into neuropathic and nociceptive (somatic) pain. Neuropathic pain is caused due to 
entrapment or direct nerve injury. Nociceptive (somatic) pain is caused by mesh-related fibrosis, mechanical pressure caused by a folded mesh, gradual mesh displacement or contraction, damaged surrounding structures such as periosteal layers, or musculotendinous tissues, or postoperative causes. ${ }^{[8]}$ Traditionally, surgeons opt to preserve the ilioinguinal nerve at all times during repair because the nerve injury is often associated with cutaneous sensory loss and chronic groin pain. On the contrary, elective division of the ilioinguinal nerve to reduce the incidence of chronic post hernioplasty pain has been recommended. Recently reported randomized controlled trials have confirmed the benefits of neurectomy in chronic post hernioplasty pain. ${ }^{[9]}$

\section{Aim of the Study}

This study aims at evaluating the long term outcomes of neuralgia and paraesthesia following routine ilioinguinal nerve excision, compared to nerve preservation while performing Lichtenstein's inguinal hernia repair and to conclude the best modality of treatment after comparison of morbidity and patient satisfaction related to these procedures and in relation to standard published material.

\section{Materials and Methods}

The present study is a randomized study of 60 cases of inguinal hernias admitted in Great Eastern Medical School and Hospital, Srikakulam, during the study period of November 2018 to November 2019.

\section{Inclusion Criteria}

All patients with a direct and indirect inguinal hernia in the age group of 18 to 80 yrs who underwent elective Lichtenstein hernia repair were included in the study.

\section{Exclusion Criteria}

1. Irreducible/ strangulated hernia.

2. H/O Diabetes, COPD, Stroke, Peripheral neuropathy.

3. Impaired cognitivefunction.
4. Recurrent hernia.

5. History of any previous lower abdominal incision.

6. Patients having preoperative inguinal neuralgia.

All patients had given informed consent, underwent routine preoperative investigations, and preparation for surgery. Then patients were randomized into two groups without the knowledge of the principal investigators.

- Group A Ilioinguinal nerve neurectomy will be done

- Group B Ilioinguinal nerve preserved Standard open mesh repair was the procedure performed under spinal anesthesia. The ilioinguinal nerve was identified in both groups and carefully preserved in group Bduring mesh placement to prevent it from being inadvertently taken in the stitches while fixing the mesh. In the neurectomy group, about $4 \mathrm{~cm}$ of the ilioinguinal nerve was excised laterally from the deep ring, and the cut ends were left alone without ligation. It was then sent for histopathology for confirmation. The rest of the operation in both groups followed the standard Lichtenstein repair.

Patients were discharged when fit and were advised to return to a healthy lifestyle except for lifting heavyweights.

Patients were followed up at one month, 4months, and 8 months after the operation. During the follow-up, the pain was assessed using the SF36 questionnaire. Paraesthesia was evaluated by the monofilament test and evaluated after comparison with the opposite side.

The age/sex incidence, mode of presentation, postoperative complications (like pain and paraesthesia), and quality of life were evaluated and compared with standard published literature. Four patients were not followed up regularly after discharge, and therefore, only one month's data were available for them and were not considered in the results of the study. The rest of the patients were followed for a period of 8 months.

Statistical Analysis

All the statistics were carried out through the 
SPSS for Windows (version 16.0). The Independent-Samples T-Test procedure compares means for two groups of cases. Excel 2016 used for mathematical calculations and graph pad calculator for statistical calculations.

\section{Observations}

Table 1: Mean Age and Standard Deviation

\begin{tabular}{|l|c|c|c|c|c|}
\hline Group & $\mathrm{N}$ & Mean & Std. Deviation & Minimum & Maximum \\
\hline Neurectomy & 30 & 50.3000 & 15.20923 & 18.00 & 78.00 \\
\hline Nerve Preservation & 30 & 45.1333 & 14.19503 & 21.00 & 72.00 \\
\hline Total & 60 & 47.7167 & 14.81650 & 18.00 & 78.00 \\
\hline
\end{tabular}

$\mathrm{CC}=0.113, \quad \mathrm{P}=0.855$

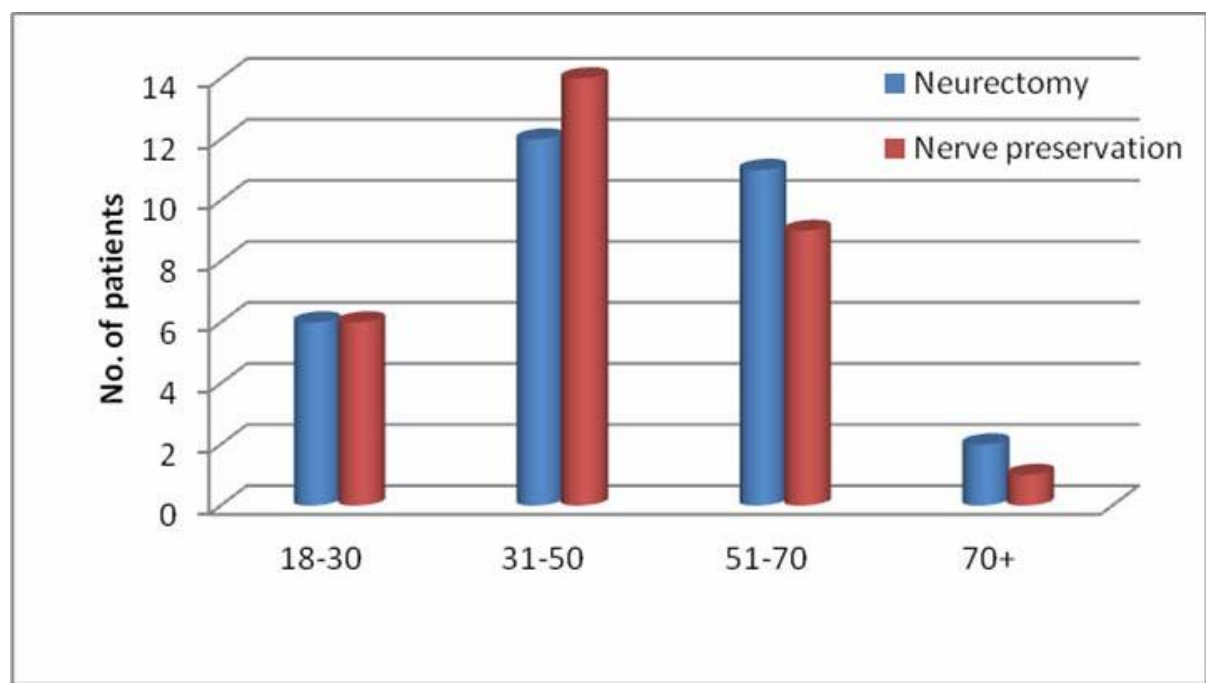

Graph 1: Age Distribution

In this study, the minimum age of the patient with the inguinal hernia was $18 \mathrm{yrs}$ in the neurectomy group and $21 \mathrm{yrs}$ in the nerve preservation group.
In comparison, the oldest is $78 \mathrm{yrs}$ in the neurectomy group and $72 \mathrm{yrs}$ in the nerve preservation group.

Table 2: Sex Incidence

\begin{tabular}{|l|c|c|}
\hline \multirow{2}{*}{ Sex } & \multicolumn{2}{|c|}{ Surgery $\mathrm{n}(\%)$} \\
\cline { 2 - 3 } & Neurectomy & Nerve preservation \\
\hline Male & $29(96.7)$ & $30(100)$ \\
\hline Female & $01(3.3)$ & 0 \\
\hline Total & $30(100)$ & $30(100)$ \\
\hline
\end{tabular}

In our study, only one female patient was present in the neurectomy group.

Table 3: Diagnosis - Type of Inguinal Hernia

\begin{tabular}{|l|c|c|}
\hline \multirow{2}{*}{ Inguinal hernia } & \multicolumn{2}{|c|}{ Surgery $\mathrm{n}(\%)$} \\
\cline { 2 - 3 } & Neurectomy & Nerve preservation \\
\hline Right Direct & $06(20.0)$ & $08(26.7)$ \\
\hline Left Direct & $05(16.7)$ & $03(10.0)$ \\
\hline RightIndirect & $12(40.0)$ & $13(43.3)$ \\
\hline LeftIndirect & $07(23.3)$ & $06(20.0)$ \\
\hline Total & $30(100)$ & $30(100)$ \\
\hline
\end{tabular}

$\mathrm{CC}=0.12, \quad \mathrm{P}=0.825$ 


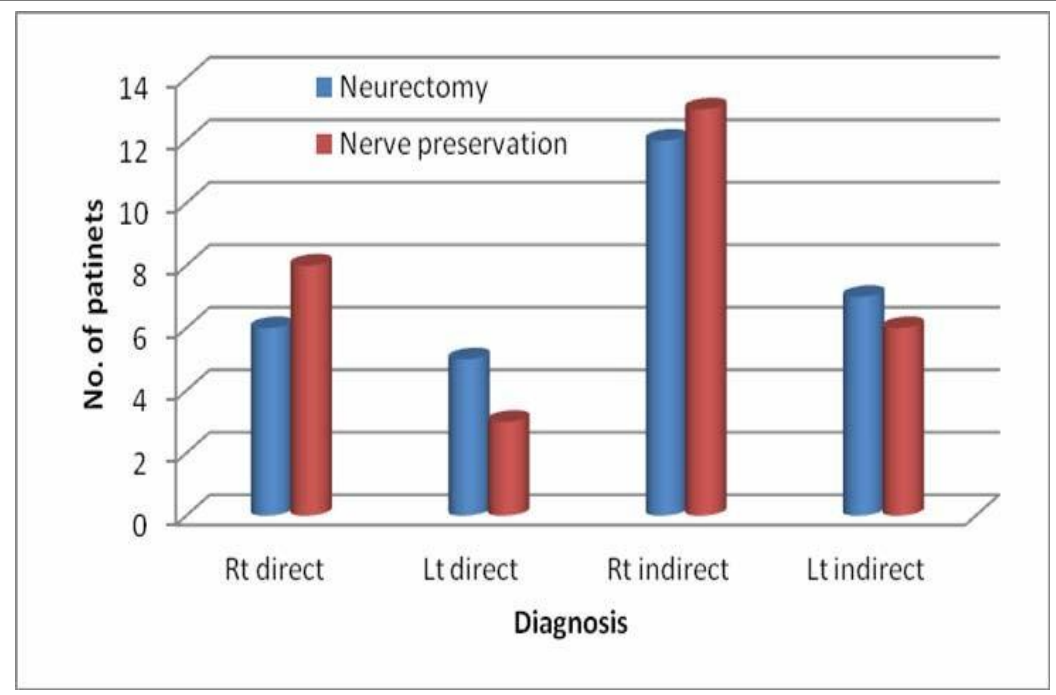

Graph 2: Type of inguinal hernia

In this study, the incidence of right indirect hernia was the highest, being $40 \%$ in the neurectomy group and $43.3 \%$ in the nerve preservation group. The least was of left direct hernia.

Table 4: Pain at Rest

\begin{tabular}{|l|c|c|c|c|}
\hline Pain at Rest & \multicolumn{3}{|c|}{ Follow up n (\%) } \\
\cline { 3 - 5 } \multicolumn{2}{|c|}{} & 1 month & 4 months & 8 months \\
\hline Neurectomy & Absent & $28(93.3)$ & $29(100)$ & $26(100)$ \\
\cline { 2 - 5 } & Present & $02(6.7)$ & 0 & 0 \\
\cline { 2 - 5 } & Total & $30(100)$ & $29(100)$ & $26(100)$ \\
\hline \multirow{3}{*}{ Nerve preservation } & Absent & $27(90.0)$ & $27(90.0)$ & $27(90.0)$ \\
\cline { 2 - 5 } & Present & $03(10.0)$ & $03(10.0)$ & $03(10.0)$ \\
\cline { 2 - 5 } & Total & $30(100)$ & $30(100)$ & $30(100)$ \\
\hline
\end{tabular}

$\mathrm{CC}=0.206, \mathrm{P}=0.05$

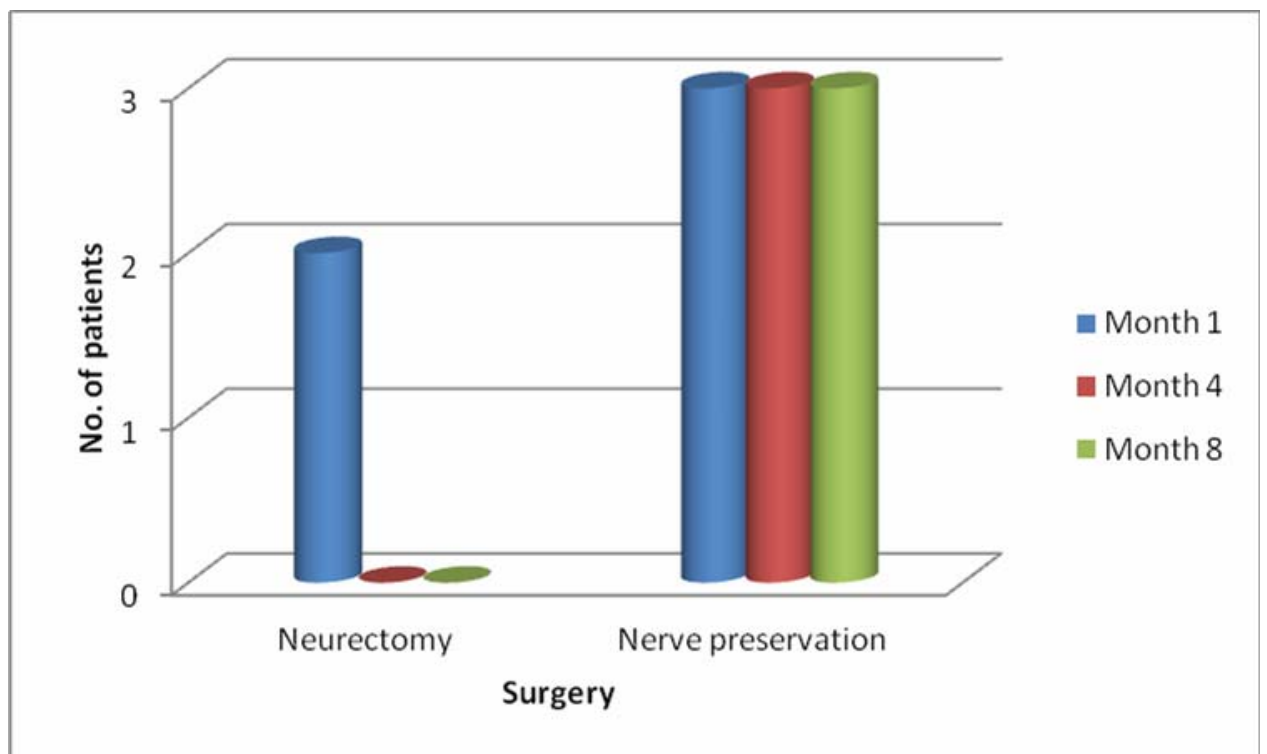

Graph 3: Pain at Rest

Pain at rest was present in $10 \%$ of the patients in the nerve preservation group after 8 months. 
Table 5: Pain experienced during Normal Daily Activities

\begin{tabular}{|l|l|c|c|c|}
\hline \multirow{2}{*}{ Pain during Normal Daily Activities } & \multicolumn{3}{|c|}{ Follow up n (\%) } \\
\cline { 3 - 6 } Neurectomy & Absent & 1 month & 4 months & 8 months \\
\cline { 2 - 5 } & Present & $03(10.0)$ & $29(100)$ & $26(100)$ \\
\hline \multirow{3}{*}{ Nerve preservation } & Total & $30(100)$ & 0 & 0 \\
\hline & Absent & $26(86.7)$ & $29(100)$ & $26(100)$ \\
\cline { 2 - 5 } & Present & $04(13.3)$ & $03(10.0)$ & $27(90.0)$ \\
\cline { 2 - 6 } & Total $=0.25, \quad \mathrm{P}=0.058$ & $30(100)$ & $30(100)$ & $30(10.0)$ \\
\hline
\end{tabular}

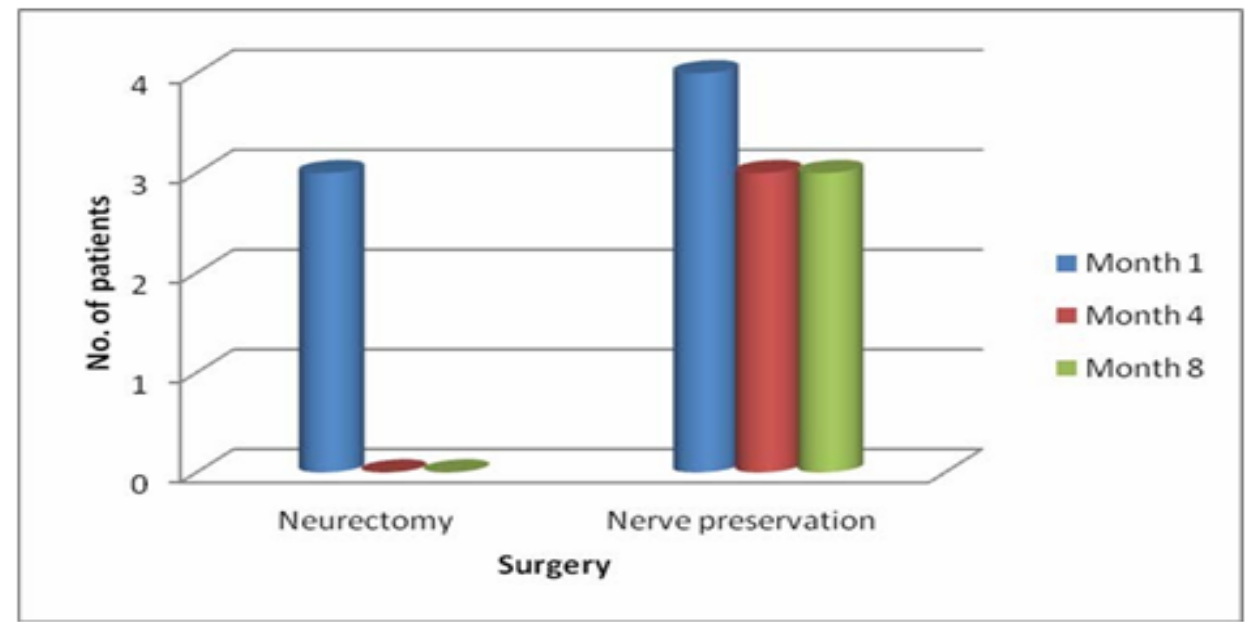

Graph 4: Pain during Normal Activities

Pain experienced during normal daily activities was present in $10 \%$ of the patients in the nerve preservation group after 8 months.

Table 6: Pain after Vigorous Activity

\begin{tabular}{|c|c|c|c|c|}
\hline \multirow{2}{*}{ Pain after Vigorous Activity } & \multicolumn{3}{|c|}{ Follow up n (\%) } \\
\cline { 2 - 5 } & Absent & 1 month & 4 months & 8 months \\
\cline { 2 - 5 } Neurectomy & Present & $15(50.0)$ & $24(82.8)$ & $22(84.6)$ \\
\cline { 2 - 5 } & Total & $30(100)$ & $29(100)$ & $4(15.4)$ \\
\hline & Absent & $13(43.3)$ & $15(50.0)$ & $19(63.3)$ \\
\cline { 2 - 5 } & Present & $17(56.7)$ & $15(50.0)$ & $11(36.7)$ \\
\cline { 2 - 5 } Nerve preservation & Total & $30(100)$ & $30(100)$ & $30(100)$ \\
\hline $\mathrm{CC}=0.337, \quad \mathrm{P}=0.004$ & \multicolumn{3}{|l}{} \\
\hline
\end{tabular}

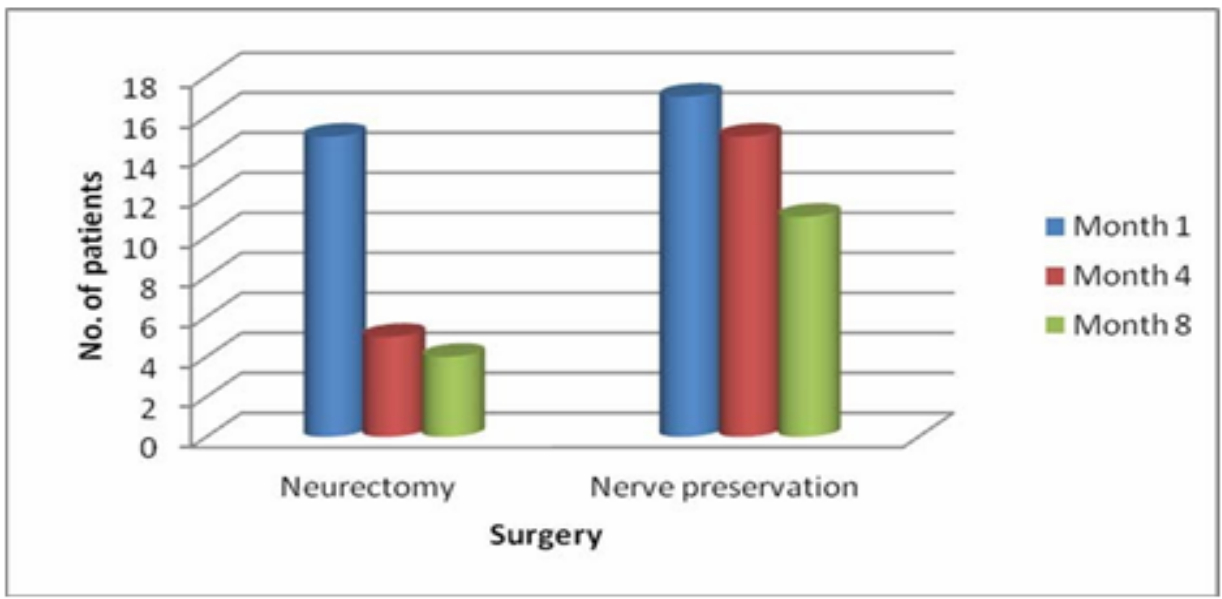

Graph 5: Pain after Vigorous Activity 
The incidence of pain after vigorous activity was almost equal in both the study groups at 1 month follow up. But the pain persisted in 11 patients in the nerve preservation group as opposed to 4 patients in the neurectomy group at 8 months follow up.

Table 7: Pain on Walking

\begin{tabular}{|c|c|c|c|c|}
\hline \multirow{2}{*}{ Pain on Walking } & \multicolumn{3}{|c|}{ Follow up n (\%) } \\
\cline { 3 - 5 } & Absent & 1 month & 4 months & 8 months \\
\cline { 2 - 5 } Neurectomy & Present & $16(53.3)$ & $23(79.3)$ & $23(88.5)$ \\
\cline { 2 - 5 } & Total & $30(100)$ & $29(100)$ & $03(11.5)$ \\
\hline \multirow{4}{*}{ Nerve preservation } & Absent & $20(66.7)$ & $24(80.0)$ & $22(73.3)$ \\
\cline { 2 - 5 } & Present & $10(33.3)$ & $06(20.0)$ & $08(26.7)$ \\
\cline { 2 - 5 } & Total & $30(100)$ & $30(100)$ & $30(100)$ \\
\hline
\end{tabular}

$\mathrm{CC}=0.368, \mathrm{P}=0.001$

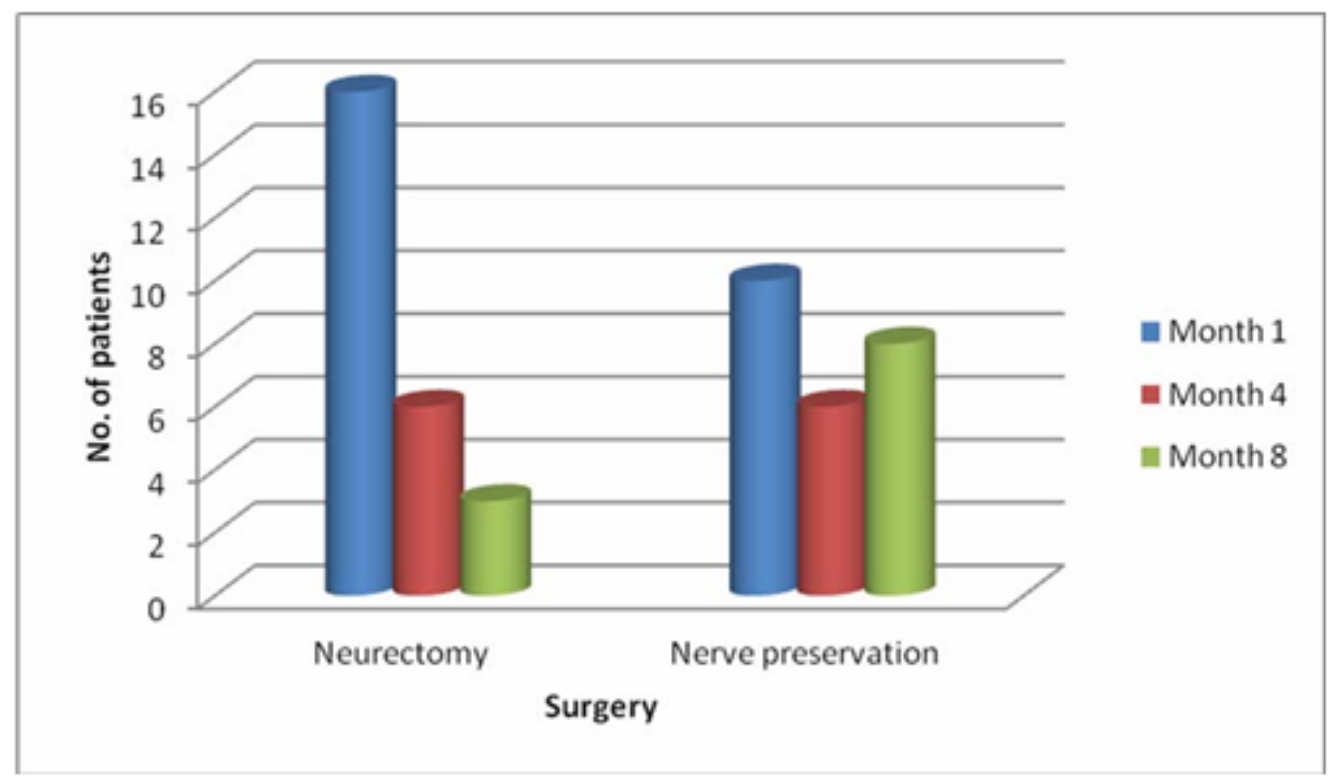

Graph 6: Pain on Walking

The incidence of pain on walking was $11.5 \%$ in the neurectomy group and $26.7 \%$ in the nerve preservation group. This difference in the incidence was found to be significant.

Table 8: Post Operative Hypoaesthesia

\begin{tabular}{|l|c|c|c|c|}
\hline Post Operative Hypoaesthesia & \multicolumn{3}{|c|}{ Follow up n (\%) } \\
\cline { 3 - 5 } & Absent & 1 month & 4 months & 8 months \\
\hline \multirow{3}{*}{ Neurectomy } & Present & $08(73.3)$ & $23(79.3)$ & $23(88.5)$ \\
\cline { 2 - 5 } & Total & $30(100)$ & $06(20.7)$ & $03(11.5)$ \\
\cline { 2 - 5 } & Absent & $27(90.0)$ & $29(96.7)$ & $29(96.7)$ \\
\cline { 2 - 5 } & Present & $03(10.0)$ & $01(3.3)$ & $01(3.3)$ \\
\cline { 2 - 5 } & Total & $30(100)$ & $30(100)$ & $30(100)$ \\
\hline \multirow{3}{*}{$\mathrm{CC}=0.152, \quad \mathrm{P}=0.367$} & & & \\
\cline { 2 - 5 } & &
\end{tabular}




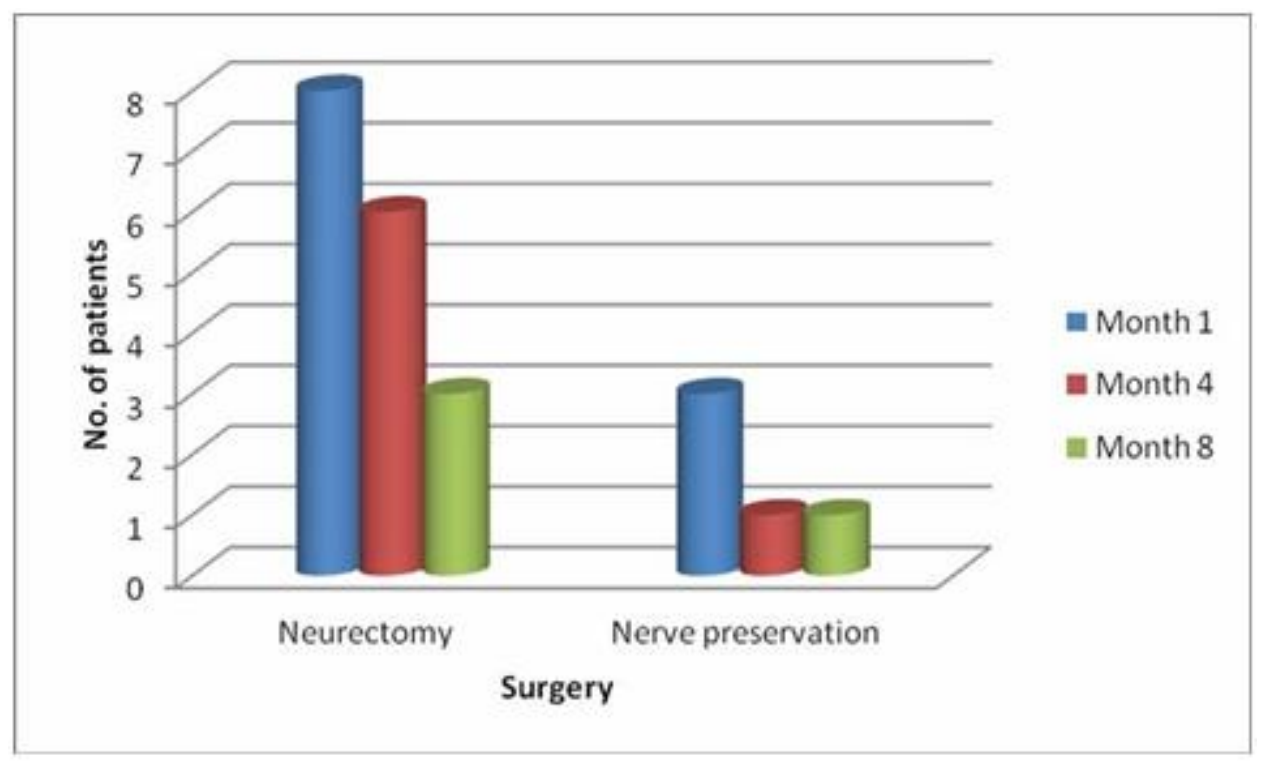

Graph 7: Post Operative Hypoaesthesia

The incidence of hypoesthesia was $11.5 \%$ in the neurectomy group, whereas it was only $3.3 \%$ in the nerve preservation group at the 8 months follow up.

Table 9: Post Operative Hyperesthesia

\begin{tabular}{|l|c|c|c|c|}
\hline Post Operative Hyperesthesia & \multicolumn{3}{|c|}{ Follow up n (\%) } \\
\cline { 3 - 5 } \multicolumn{2}{|c|}{} & 1 month & 4 months & 8 months \\
\hline \multirow{3}{*}{ Neurectomy } & Absent & $22(73.3)$ & $26(89.7)$ & $26(100)$ \\
\cline { 2 - 5 } & Present & $08(26.7)$ & $03(10.3)$ & 0 \\
\cline { 2 - 5 } & Total & $30(100)$ & $29(100)$ & $26(100)$ \\
\hline \multirow{3}{*}{ Nerve preservation } & Absent & $19(63.3)$ & $29(96.7)$ & $29(96.7)$ \\
\cline { 2 - 5 } & Present & $11(36.7)$ & $01(3.3)$ & $01(3.3)$ \\
\cline { 2 - 5 } & Total & $30(100)$ & $30(100)$ & $30(100)$ \\
\hline
\end{tabular}

$\mathrm{CC}=0.310, \mathrm{P}=0.061$

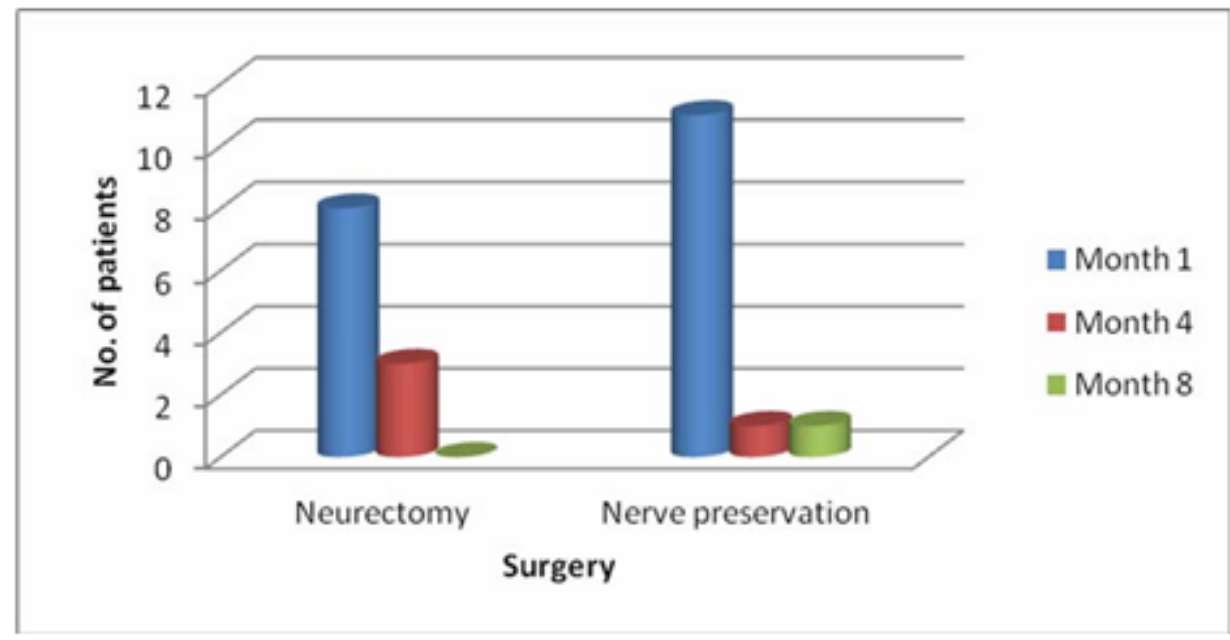

Graph 8: Post Operative Hyperesthesia

The incidence of hyperesthesia was high in both the study groups after 1 month follow up. At 8 months follow up, only one patient in the nerve preservation group had persistent hyperesthesia at the operated site. 
Table 10: Quality of Life - Physical Functioning

\begin{tabular}{|l|c|c|}
\hline \multirow{2}{*}{ Physical Functioning } & \multicolumn{2}{|c|}{ Surgery n(\%) } \\
\cline { 2 - 3 } & Neurectomy & Nerve preservation \\
\hline No Limitation of Activities & $26(100 \%)$ & $27(90 \%)$ \\
\hline Mild Limitation of Activities & 0 & $03(10 \%)$ \\
\hline Severe Limitation of Activities & 0 & 0 \\
\hline Total & $26(100 \%)$ & $30(1$ majority $000 \%)$ \\
\hline
\end{tabular}

$\mathrm{CC}=0.296, \quad \mathrm{P}=0.097$

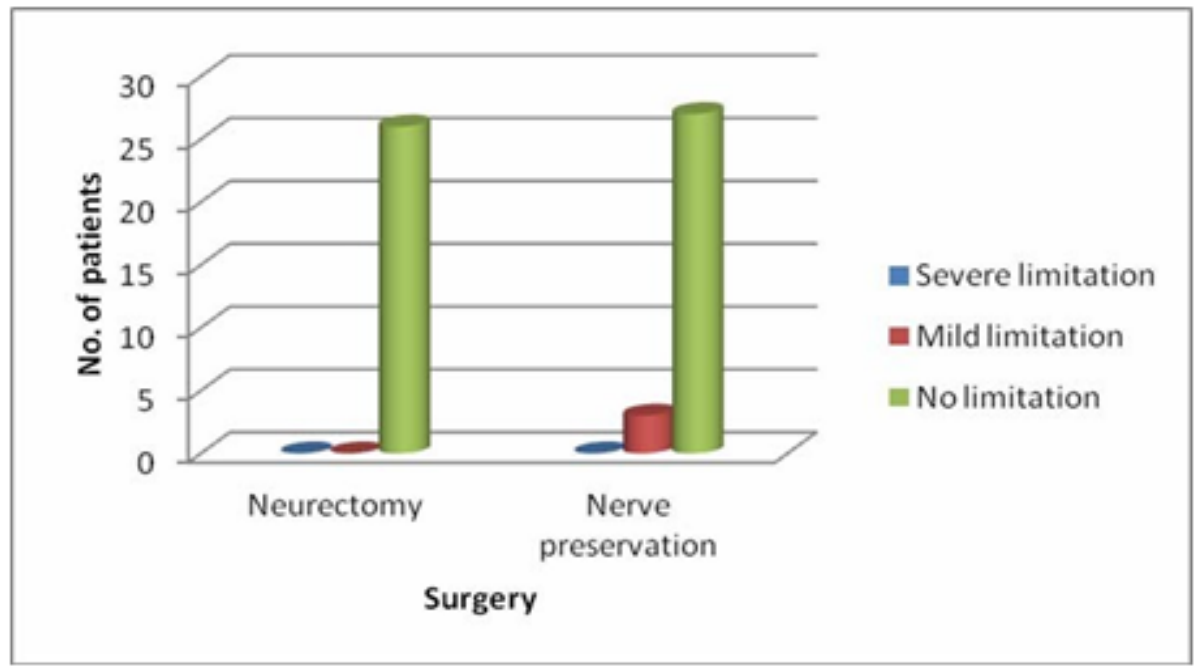

Graph 9: Quality of Life- Physical Functioning

Majority of the patients had no effect on their physical functioning postoperatively, except 3 in the nerve preservation group, who complained of mild limitation of their day to day work due to post-operative pain.

Table 11: Quality of Life- General Health

\begin{tabular}{|l|c|c|}
\hline \multirow{2}{*}{ General Health } & \multicolumn{2}{|c|}{ Surgery n (\%) } \\
\cline { 2 - 3 } & Neurectomy & Nerve preservation \\
\hline Satisfactory & $26(100 \%)$ & $27(90 \%)$ \\
\hline Not Satisfactory & 0 & $03(10 \%)$ \\
\hline Total & $26(100 \%)$ & $30(100 \%)$ \\
\hline
\end{tabular}

$$
\mathrm{CC}=0.296, \mathrm{P}=0.097
$$

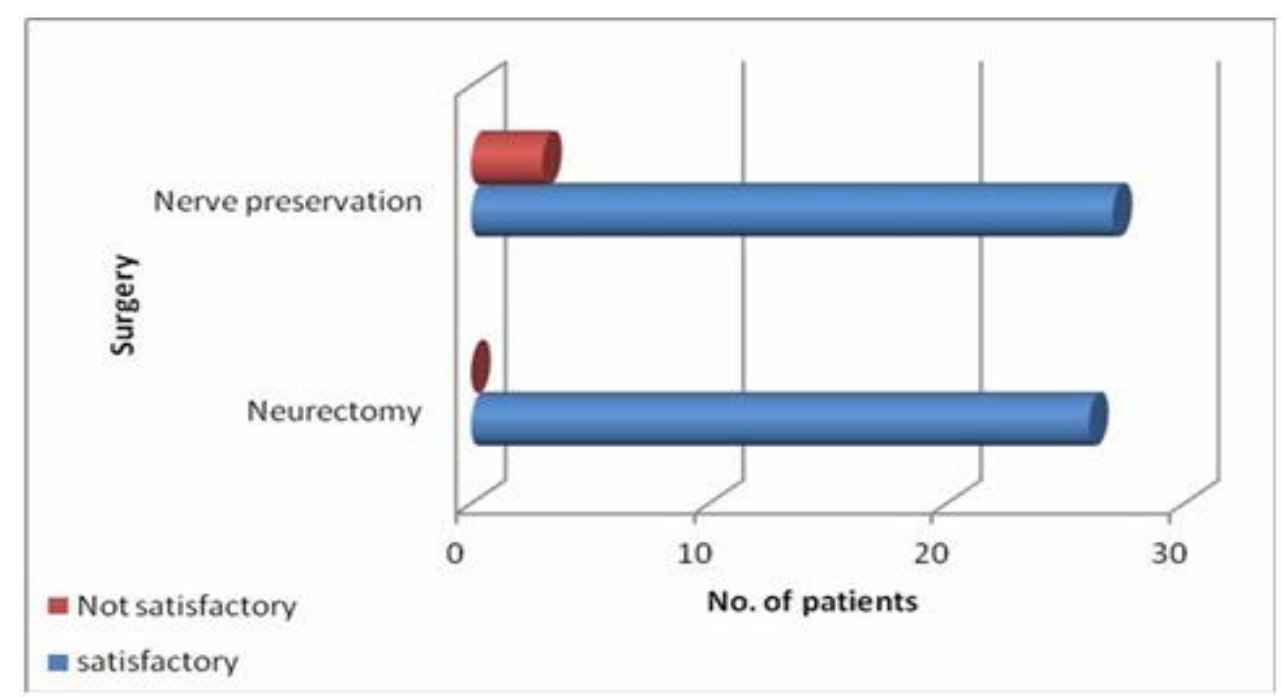

Graph 10: Quality of Life- General Health 
General health was found to be unsatisfactory only in 3 patients belonging to nerve preservation group in the entire study

Table 12: Quality of Life- Bodily Pain

\begin{tabular}{|l|c|c|}
\hline \multirow{2}{*}{ Bodily Pain } & \multicolumn{2}{|c|}{ Surgery $\mathrm{n}(\%)$} \\
\cline { 2 - 3 } & Neurectomy & Nerve preservation \\
\hline No Pain & $23(88.5 \%)$ & $22(73.3 \%)$ \\
\hline Mild Pain & $03(11.5 \%)$ & $05(16.7 \%)$ \\
\hline Moderate Pain & 0 & $03(10 \%)$ \\
\hline Severe Pain & 0 & 0 \\
\hline Total & $26(100 \%)$ & $30(100 \%)$ \\
\hline
\end{tabular}

$\mathrm{CC}=0.234, \mathrm{P}=0.097$

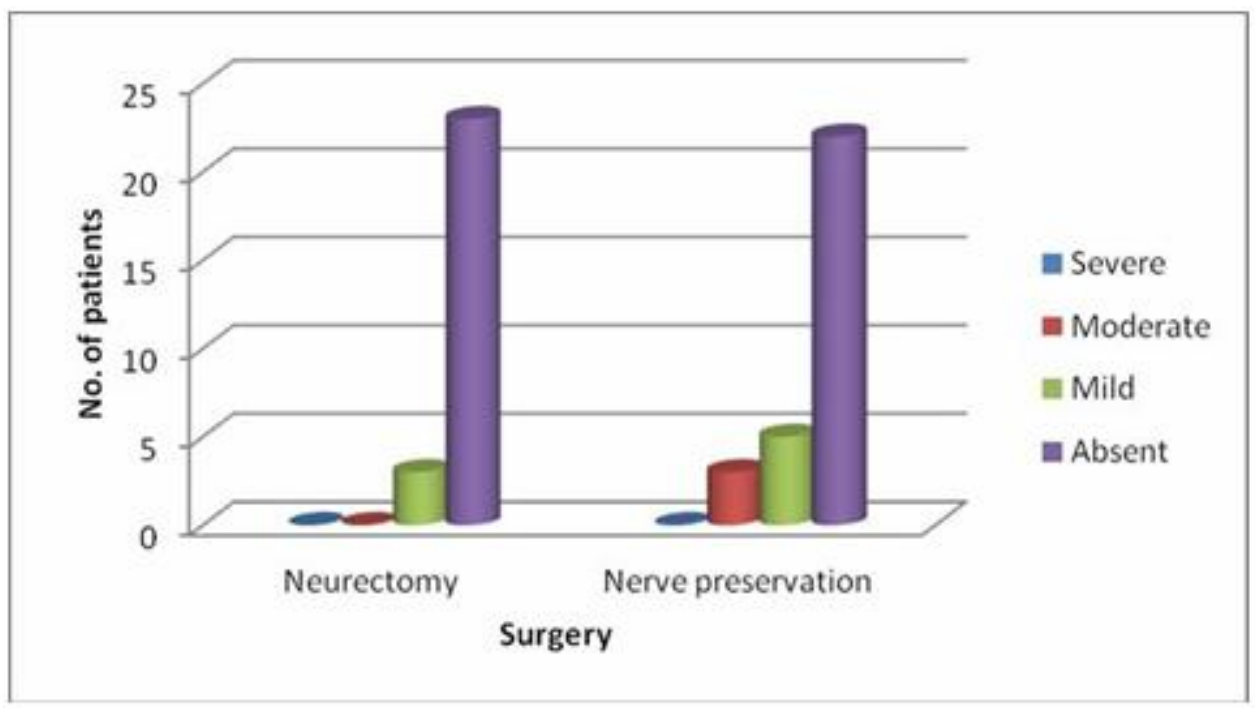

Graph 11: Quality of Life-Bodily Pain

8 patients experienced mild body pain following surgery, out of which, majority were in the nerve preservation group (5/8). Only 3 patients had severe body pain in the nerve preservation group.

\section{Discussion}

Although chronic pain post hernioplasty can be controlled with analgesics, it has emerged as a significant clinical problem after an open mesh repair, significantly affecting patient's satisfaction and quality of life. ${ }^{[10-12]}$ The rate of chronic pain after inguinal hernia mesh repair can reach $51.6 \% .{ }^{[13]}$ Reasons for post hernioplasty chronic pain are mostly unclear; however, one of the proposed mechanisms is the inflammation and fibrosis induced by the mesh, which is close to the ilioinguinal nerve. ${ }^{[14]}$ Additionally, there could also be an unintentional injury or strangulation of the ilioinguinal nerve during suturing.

\section{Patient Characteristics}

Age

In our study, the mean age of the individuals in the neurectomy group was 50 years, and the mean age of the individuals in the nerve preservation group was 45 years. When compared to a randomized controlled study by Malekpour $\mathrm{F}$ et al. ${ }^{[9]}$, wherein the mean study age was $45 \pm$ 18years.

Sex

Of the 60 patients in the study, 59 were males. Only one female patient was present in the study, included in the neurectomy group. This is comparable with the study done by Malekpour $\mathrm{F}$ et al. ${ }^{[9]}$, in which $5 \%(6 / 120)$ of the study group were females. However, in the study done by Picchio et al. ${ }^{[15]}, 27$ out of the 813 patients were females. The sex incidence of our study does not correlate with the study above as a large number 
of patients were included in their study, and also the reluctance of women in our demographic to seek medical attention.

\section{Pain at Rest}

In the neurectomy study group, pain at rest was present in $6.7 \%$ patients at 1 month, which subsided by 8 months, whereas in the nerve preservation study group, it was present in $10 \%$ patients at 1 month and persisted upto 8 months postoperatively. In the study by Picchio et al. ${ }^{[15]}$, pain occurred in 5\% and $6 \%$ of the studied patients in the neurectomy and nerve preservation groups, respectively, at 1 month. This subsided to $3 \%$ (neurectomy study group) and 2\%(nerve preservation group) of patients at 1year.

Incidence of chronic groin pain at rest was similar between the neurectomy and nerve preservation groups $(\mathrm{P}=0.153)$, which compliment the findings of Mui et al. ${ }^{[16]}(\mathrm{P}=0.056)$ and Picchio et al. $^{[15]}(\mathrm{P}=0.56)$. This observation also had supporting data from another study by Hsu et al. $^{[17]}$

\section{Pain Experienced During Normal Daily Activities:}

In our study, at the end of 1 month, the pain was present in $10 \%$ of patients in the neurectomy study group and $13.3 \%$ of patients in the nerve preservation study group. After 8 months, the incidence of pain reduced to $0 \%$ in the first group and $10 \%$ in the second group. Mui et al. ${ }^{[16]}$ found a high incidence of pain at the end of the first month, in both groups (66\% v/s 74.5\%). However, the incidence of pain drastically reduced by 6 months $(0 \% \mathrm{v} / \mathrm{s} 2 \%)$.

The results are consistent with those of Mui et al. ${ }^{[16]}(\mathrm{P}=0.24)$ and were found to be insignificant between both the study groups $(\mathrm{P}=0.058)$.

\section{Pain after vigorous activity and on walking:}

Notable differences were found in the incidence of pain after vigorous activity, between the neurectomy group and the nerve preservation group (15.4\% v/s 36.7\%; $\mathrm{P}=0.004)$, as well as in the incidence of pain on walking $(11.5 \% \mathrm{v} / \mathrm{s}$ $26.7 \%$; $\mathrm{P}=0.001$ ) with a noticeable decrease in the incidence of pain in the neurectomy group over the 8 month follow up period.

These findings are consistent with those of Dittrick et $\mathrm{al}^{[2]}(3 \% \mathrm{v} / \mathrm{s} 25 \% ; \mathrm{P}=0.003)$ and Malekpour et $\mathrm{al}^{[9]}(6 \% \mathrm{v} / \mathrm{s} 21 \% ; \mathrm{P}=0.033)$; however, Picchio et al ${ }^{[15]}$ reported an almost equal incidence of pain after one year (18\% v/s 21\%). Ravichandran et al. ${ }^{[14]}$, in a pilot study in the year 2000, compared the incidence of pain after preservation or division of the ilioinguinal nerve in hernia repair and found that the differences in both the groups were insignificant. These results were limited by a small sample size, which therefore fails to confer an adequate and strong statisticalpower.

\section{Postoperative Paraesthesia:}

In our study, at the end of the first month of follow up, incidence of hypoesthesia was higher in the neurectomy group ( $26 \% \mathrm{v} / \mathrm{s} 10.0 \%$ ), but hyperesthesia was higher in the nerve preservation group $(26.7 \% \mathrm{v} / \mathrm{s} 36.7 \%)$. At 8 months of follow up, the overall incidence of paraesthesia decreased, but hypoesthesia persisted in $11.5 \%$ patients of the neurectomy group as opposed to $3.3 \%$ patients of the nerve preservation group.

These results are comparable with those of Mui et $\mathrm{al}^{[16]}(26 \% \mathrm{v} / \mathrm{s} 18.4 \%)$ and G.W. Dittrick et al ${ }^{[2]}$ $(13 \% \mathrm{v} / \mathrm{s} 5 \%)$. The study of Abdullah et al. ${ }^{[18]}$ complements this finding, wherein the preservation or division of the intercostobrachial nerve in patients undergoing axillary node dissection (for invasive breast cancer), did not change the incidence of postoperative numbness. The explanation is that when sensory nerves are excised, there are usually abrupt patterns of numbness followed by a gradual recovery, based on the formation of collateral nerves.

\section{Quality of Life:}

In this study, there was no notable difference in the health-related quality of life between the two study groups, which complements the findings of Mui et al. ${ }^{[16]}$.

\section{Conclusion}

The present study has several limitations. Small sample size and short follow up period in limits 
the extension of result from the current study is relatively short. Prophylactic studies in larger study samples with longer follow-up are needed. In summary, prophylactic excision of the ilioinguinal nerve during Lichtenstein mesh hernia repair decreases the incidence of chronic groin pain after surgery, without additional morbidities. Thus, we suggest routine ilioinguinal neurectomy to be a reasonable option in open mesh repair of inguinal hernia ilioinguinal neurectomy in patients undergoing anterior inguinal hernia mesh repair.

\section{References}

1. [No authors listed]. Classification of chronic pain. Descriptions of chronic pain syndromes and definitions of pain terms. Prepared by the International Association for the Study of Pain, Subcommittee on Taxonomy. Pain Suppl 1986 3;S1-S226.

2. Dittrick GW, Ridl K. Routine ilioinguinal nerve excision in inguinal hernia repairs. Am J Surg2004;188:736-40.

3. Rutkow IM, Robbins AW. Demographic, classificatory, and socioeconomic aspects of hernia repair in the United States. Surg Clin North Am 1993;73:413.

4. Sakorafas GH, Halikias I, Nissotakis C, Kotsifopoulos N, Stavrou A, Antonopoulos $\mathrm{C}$,et al. Open tension-free repair of inguinal hernias; the Lichtenstein technique. BMC surgery. 2001 Dec;1(1):3.

5. Lichtenstein IL, Shulman AG,Amid PK, Montllor MM. The tension-free hernioplasty. Am J Surg. Feb 1;157(2):188-93.

6. Stoppa RE. The treatment of complicated groin and incisional hernias. World JSurg 1989;13:545-554.

7. Janu PG, Sellers KD, Mangiante EC. Recurrent inguinal hernia. Preferred operative approach. Am Surg1998;64:569573.

8. Amid PK. Causes, prevention, and surgical treatment of post herniorrhaphy neuropathic inguinodynia: Triple neurectomy with proximal end implantation. Hernia. 2004;8(4):343-9.

9. Malekpour F, Mirhashemi SH, Hajinasrolah E, Salehi N, Khoshkar A, Kolahi AA. Ilioinguinal nerve excision in open mesh repair of inguinal herniaresults of a randomized clinical trial: simple solution for a difficult problem? Am J Surg. 2008;195(6):735-40.

10. Callesen T, Bech K, Kehlet H. Prospective study of chronic pain after groin hernia repair. Br J Surg. 1999;86(12):1528-31.

11. Bay-Nielsen M, Perkins FM, Kehlet H. Pain, and Functional Impairment 1 Year After Inguinal Herniorrhaphy: A Nationwide Questionnaire Study. Ann Surg. 2001;233(1):1.

12. Poobalan AS, Bruce J, King PM, Chambers WA, Krukowski ZH, Smith WCS. Chronic pain and quality of life following open inguinal hernia repair. $\mathrm{Br} \mathrm{J}$ Surg. 2001;88(8):1122-6.

13. O'Dwyer PJ, Kingsnorth AN, Molloy RG, Small PK, Lammers B, Horeyseck G. Randomized clinical trial assessing the impact of a lightweight or heavyweight mesh on chronic pain after inguinal hernia repair. Br J Surg. 2005;92(2):166-70.

14. Ravichandran D, Kalambe BG, Pain JA. Pilot randomized controlled study of preservation or division of ilioinguinal nerve in open mesh repair of inguinal hernia. Br J Surg. 2000;87(9):1166-7.

15. Picchio M, Marcello P, Palimento D. Randomized controlled trial of preservation or elective division of ilioinguinal nerve on open inguinal hernia repair with polypropylene mesh. Arch Surg2004;139:755-8.

16. Wilfred L M Mui, Calvin S H, Terence M K Fung, Frances KY Cheung, Chi-Ming Wong,Tze-Hin Ma, et al. Ilioinguinal nerve excision in open mesh repair of inguinal hernia-results of a randomized 
clinical trial: a simple solution for a difficult problem. Am J Surg 2008 Jun;195(6):735-40.

17. Hsu W, Chen C-S, Lee H-C, Liang H-H, Kuo L-J, Wei P-L, et al. Preservation Versus Division of Ilioinguinal Nerve on Open Mesh Repair of Inguinal Hernia: A Meta-analysis of Randomized Controlled Trials. World J Surg. 2012;36(10):2311-9.

18. Abdullah TI, Iddon J, Barr L. Prospective randomized controlled trial of preservation of the intercostobrachial nerve during axillary node clearance for breast cancer. Br J Surg1998;85:1443-5. 